\title{
Predictive role of preoperative hydronephrosis on poor pathological outcomes and prognosis in upper tract urothelial carcinoma patients: Experience from a nationwide high-volume center in China
}

\author{
ZHENG ZHANG* ${ }^{*}$ DONG FANG ${ }^{*}$, XIAOPENG CHEN, XUESONG LI", \\ GENGYAN XIONG, LEI ZHANG, QUN HE and LIQUN ZHOU \\ Department of Urology, Peking University First Hospital, Institute of Urology, \\ Peking University, National Urological Cancer Center, Beijing 100034, P.R. China
}

Received October 10, 2014; Accepted July 10, 2015

DOI: $10.3892 / \mathrm{ol} .2015 .3653$

\begin{abstract}
To validate the predictive value of preoperative hydronephrosis (HN) with regard to clinicopathological outcome and prognosis in a large cohort of upper tract urothelial carcinoma (UTUC) patients, a retrospective analysis was conducted using the clinicopathological data of 520 consecutive patients treated between 2000 and 2010 at a nationwide high-volume center in China. Preoperative computed tomography or magnetic resonance imaging scans were evaluated for the presence of ipsilateral $\mathrm{HN}$, and the associations between $\mathrm{HN}$ and pathological outcomes, patient survival and urinary tract recurrences were assessed. Ipsilateral $\mathrm{HN}$ was present in 271 patients (52.1\%). Preoperative $\mathrm{HN}$ was associated with advanced age $(\mathrm{P}=0.007)$, sessile tumor architecture $(\mathrm{P}<0.001)$, ureteral location $(\mathrm{P}<0.001)$, higher tumor stage $(\mathrm{P}<0.001)$ and higher histological grade $(\mathrm{P}=0.002)$. Univariate and multivariate analyses revealed that poorer cancer-specific survival (CSS) and overall survival (OS) times were correlated with preoperative $\mathrm{HN}(\mathrm{P}=0.004$ and $\mathrm{P}=0.009$, respectively). The 5-year CSS and OS rates for patients with HN were 86.9 and $86.2 \%$, respectively, compared to 93.3 and $91.9 \%$ for patients without HN. For patients with muscle-invasive disease, HN remained a risk factor for poor CSS and OS $(\mathrm{P}=0.009$ and
\end{abstract}

Correspondence to: Dr Xuesong Li or Dr Liqun Zhou, Department of Urology, Peking University First Hospital, Institute of Urology, Peking University, National Urological Cancer Center, 8 Xishiku Street, Xicheng, Beijing 100034, P.R. China

E-mail: pineneedle@sina.com

E-mail: zhoulqmail@sina.com

*Contributed equally

Key words: pathological outcome, preoperative hydronephrosis, prognosis, radical nephroureterectomy, upper tract urothelial carcinoma
$\mathrm{P}=0.012$, respectively). No association was identified between $\mathrm{HN}$ and bladder recurrence $(\mathrm{P}=0.552)$ or the development of contralateral upper tract carcinoma $(\mathrm{P}=0.164)$. The findings indicated that preoperative $\mathrm{HN}$ is prevalent in UTUC. The presence of preoperative $\mathrm{HN}$ predicted poorer pathological outcomes and was a significant risk factor affecting survival. The evaluation of HN may be informative for decisions concerning surgical options, and the presence of HN should raise the possibility of employing an aggressive treatment approach.

\section{Introduction}

Urothelial carcinoma is the second most common urological malignancy worldwide, after prostate cancer (1). A distinguishing feature of urothelial carcinomas is their multiple foci, which cause the tumors to appear synchronously or sequentially throughout the urinary tract, including the upper urinary tracts (renal pelvis or ureter), bladder and urethra (2). Upper tract urothelial carcinomas (UTUC) are uncommon and account for only 5-10\% of urothelial carcinomas (3). At present, tobacco exposure is considered the most important risk factor for urothelial carcinoma $(4,5)$. Gross or microscopic hematuria is the presenting symptom in 70-80\% of UTUC patients (6). Furthermore, at the time of diagnosis $40-50 \%$ of patients exhibit in situ [pTa to pT1 (7)] disease, 50-60\% of patients exhibit invasive or advanced disease [p $\geq \mathrm{T} 2$ (7)], and $\sim 25 \%$ patients already exhibit regional metastasis $(8,9)$. Radical nephroureterectomy (RNU) with excision of the bladder cuff is the gold-standard treatment for UTUC (3). However, alternative treatments include ureteroscopic ablation, percutaneous resection and segmental resection (10). The oncological outcomes for patients with high-grade or non-organ-confined disease remain poor, with 5-year cancer-specific survival rates of $<60 \%$; while for patients with non-muscle-invasive lesions, the 5-year recurrence-free survival rate is $88.0-91.8 \%$ (11). For patients with low-grade carcinomas, conservative strategies, including segmental ureterectomy or endoscopic management, provide cancer-specific survival (CCS) and overall survival 
(OS) rates equivalent to that achieved using RNU $(12,13)$, with a 5-year cancer-specific survival rate of $>93 \%$ (14), whereas patients at high-risk (pT3 or $\mathrm{N}+$ ) may benefit from neoadjuvant chemotherapy $(15,16)$. The ability to accurately predict pathological outcomes prior to initiating therapy may aid in clinical risk stratification and the selection of therapeutic strategies.

Ipsilateral hydronephrosis (HN) is common in UTUC patients, and may be attributed to one of several factors, including luminal obstruction, intramural invasion or extrinsic compression (17). The presence of ipsilateral HN in patients with bladder cancer is a predictive factor for poor pathological outcome and poor prognosis (18-20); however, at present, no consensus has been reached regarding the predictive role of the presence of HN in UTUC patients. Although HN has been reported to be associated with advanced disease (17,21-24), only two studies demonstrated a correlation between $\mathrm{HN}$ and poor prognosis based on small sample $(17,25)$.

Our previous work has revealed associations between HN and muscle-invasive and grade 3 diseases (21). In the present study, after revising our database to include the follow-up information of patients treated between 2000 and 2010, we sought to validate the predictive value of preoperative $\mathrm{HN}$ on clinicopathological outcome and prognosis with the aim of improving clinical risk stratification and, thus, the ability to provide more optimal and personalized risk-informed therapeutic options.

\section{Materials and methods}

Patient selection. The clinicopathological data of consecutive UTUC patients treated between 2000 and 2010 at Peking University First Hospital (Beijing, China) were collected. Among the 631 patients with complete follow-up, 111 were excluded from the analysis: 25 with bilateral synchronous UTUCs, 54 who underwent alternative surgeries rather than RNU, 28 with a follow-up period of $<12$ months, 2 with metastatic disease and 2 with positive surgical margins. A total of 520 patients were finally enrolled for evaluation. All patients were diagnosed using computed tomography (CT) or magnetic resonance imaging (MRI), urological ultrasound and ureteroscopy with or without biopsy. None of these patients received neoadjuvant chemotherapy, however, for certain patients, adjuvant chemotherapy or radiotherapy was administered when evidence of distant metastasis or retroperitoneal recurrence was documented. All patients underwent surgery within two months after the occurrence of symptoms. Ethical approval was obtained from Peking University Institutional Review Board (IRB00001052-13057).

Ipsilateral HN status. Ipsilateral $\mathrm{HN}$ was assessed by upper urinary tract imaging, including $\mathrm{CT}$ with or without intravenous contrast in 510 patients, and MRI with or without intravenous contrast in 10 patients. Only imaging studies performed within 6 weeks of RNU and which were evaluated for HN by radiologists blinded to clinical outcomes were considered. As $\sim 100$ CT films were not available for re-evaluation, two authors (Dr Xuesong Li and Dr Gengyan Xiong) blinded to the radiology reports reviewed the 10 MRI films and $100 \mathrm{CT}$ films independently. The concordance between the two observers in assessing presence or absence of $\mathrm{HN}$ was $95.5 \%$ and, by consensus decision, the concordance between re-evaluation and primary reports was $97.3 \%$.
The evaluation criteria for assessing the presence or absence of $\mathrm{HN}$ were similar to those of a previous study (23). For renal pelvic lesions, patients with hydrocalycosis were included in the cohort of patients considered to have HN. A hydrocalyx was defined as any degree of dilation within a focal calyx, with or without the presence of obvious obstruction at the draining infundibulum. For ureteral tumors, any degree of dilation in any component of the ureter or associated renal unit was classified as HN. To avoid small subgroups and heterogeneity with respect to the grading of $\mathrm{HN}$, the status of $\mathrm{HN}$ was evaluated strictly as present or absent in the current analysis.

Patients evaluation. All pathological specimens were re-reviewed by a dedicated genitourinary pathologist (Dr Qun He) to unify the reproducibility of the diagnosis. Tumor stage was assessed according to the 2002 Union for International Cancer Control TNM classification of malignant tumors (10). Tumor grade was assessed according to the World Health Organization classification of 1973 (10). Tumor architecture was defined as papillary or sessile by examination of the final specimen. Tumor location was divided into two areas (renal pelvis and ureter) based on the site of the dominant lesion. Tumor multifocality was defined as the synchronous presence of two or more pathologically confirmed macroscopic tumors in any location. The estimated glomerular filtration rate was calculated using the modified glomerular filtration rate estimating equation for Chinese patients (26).

Follow-up schedule. Of the total cohort $(\mathrm{n}=631), 520$ patients were included in the current analyses. For patients who were followed-up at our institute, the follow-up regimen of the affected patients included cystoscopy every 3 months for the first 3 years; cystoscopy intervals were extended to 1 year thereafter. Chest X-ray, serum creatinine level and abdominal ultrasound or CT were examined concurrently. The impact of preoperative HN on CSS, OS, bladder recurrence-free survival and contralateral carcinoma-free survival times was determined. Bladder recurrence was defined as the detection of a subsequent bladder tumor during cystoscopy and confirmation by pathology, while contralateral carcinoma was defined as urothelial carcinoma in the contralateral upper urinary tract. The causes of patient mortality were determined by the treating physicians.

Statistical analysis. All statistical tests were performed using SPSS software version 20.0 (IBM SPSS, Armonk, NY, USA), and the threshold for statistical significance was set at $\mathrm{P}<0.05$. The Pearson test and $\chi^{2}$ test were used to assess the distribution of categorical variables, and the Mann-Whitney U test was used for continuous variables. Univariate analysis using the log-rank test and multivariate analysis using Cox's proportional hazards regression model were also conducted. Only variables that were indicated to be significant upon univariate analysis were considered for the multivariate analysis.

\section{Results}

Patient clinical and pathological characteristics and $H N$. The clinical and pathological data of the included patients and their association with $\mathrm{HN}$ are shown in Table I. Of the 520 patients enrolled, ipsilateral $\mathrm{HN}$ was present in 271 patients $(52.1 \%)$. 
Table I. Patient clinical and pathological characteristics and ipsilateral hydronephrosis.

\begin{tabular}{|c|c|c|c|c|}
\hline \multirow[b]{2}{*}{ Characteristic } & \multicolumn{2}{|c|}{ Ipsilateral hydronephrosis, n (\%) } & \multirow[b]{2}{*}{$\chi^{2}$} & \multirow[b]{2}{*}{ P-value } \\
\hline & Absent & Present & & \\
\hline Gender & & & 0.004 & 0.951 \\
\hline Male & $110(21.15)$ & $119(22.88)$ & & \\
\hline Female & $139(26.73)$ & $152(29.23)$ & & \\
\hline Age, years & & & 7.320 & $0.007^{\mathrm{a}}$ \\
\hline$<70$ & $157(30.19)$ & $139(26.73)$ & & \\
\hline$\geq 70$ & $92(17.69)$ & $132(25.38)$ & & \\
\hline Preoperative renal function & & & 3.221 & 0.522 \\
\hline 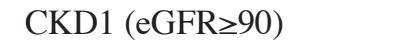 & $26(5.00)$ & $18(3.46)$ & & \\
\hline CKD2 (90>eGFR $\geq 60)$ & $88(16.92)$ & $96(18.46)$ & & \\
\hline CKD3 (60>eGFR $\geq 30)$ & $106(20.38)$ & $117(22.50)$ & & \\
\hline 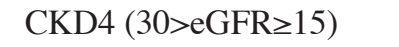 & $13(2.50)$ & $19(3.65)$ & & \\
\hline CKD5 (eGFR<15) & $16(3.08)$ & $21(4.04)$ & & \\
\hline Urinary cytology & & & 0.675 & 0.714 \\
\hline Negative & $57(10.96)$ & $58(11.15)$ & & \\
\hline Positive & $122(23.46)$ & $128(24.62)$ & & \\
\hline Missing data & $70(13.46)$ & $85(16.35)$ & & \\
\hline Tumor architecture & & & 16.604 & $0.000^{\mathrm{a}}$ \\
\hline Papillary & $219(42.12)$ & $200(38.46)$ & & \\
\hline Sessile & $30(5.77)$ & $71(13.65)$ & & \\
\hline Multifocality & & & 2.788 & 0.095 \\
\hline No & $205(39.42)$ & $207(39.81)$ & & \\
\hline Yes & $44(8.46)$ & $64(12.31)$ & & \\
\hline Location & & & 145.028 & $0.000^{\mathrm{a}}$ \\
\hline Ureter & $54(10.38)$ & $202(38.85)$ & & \\
\hline Pelvis & $195(37.50)$ & $69(13.27)$ & & \\
\hline Tumor stage & & & 24.199 & $0.000^{\mathrm{a}}$ \\
\hline $\mathrm{Ta}$ & $22(4.23)$ & $8(1.54)$ & & \\
\hline $\mathrm{T} 1$ & $76(14.62)$ & $74(14.23)$ & & \\
\hline $\mathrm{T} 2$ & 75 (14.42) & $127(24.42)$ & & \\
\hline $\mathrm{T} 3$ & $76(14.62)$ & $59(11.35)$ & & \\
\hline $\mathrm{T} 4$ & $0(0.00)$ & $3(0.58)$ & & \\
\hline Node stage & & & 2.066 & 0.356 \\
\hline N0 & $20(3.85)$ & $31(5.96)$ & & \\
\hline $\mathrm{Nx}$ & $225(43.27)$ & $233(42.88)$ & & \\
\hline $\mathrm{N}+$ & $4(0.77)$ & $6(1.15)$ & & \\
\hline Tumor grade & & & 12.568 & $0.002^{\mathrm{a}}$ \\
\hline G1 & $10(1.92)$ & $9(1.73)$ & & \\
\hline $\mathrm{G} 2$ & $167(32.12)$ & $143(27.50)$ & & \\
\hline G3 & $72(13.85)$ & $119(22.88)$ & & \\
\hline Tumor necrosis & & & 0.286 & 0.593 \\
\hline No & $225(43.27)$ & $241(46.35)$ & & \\
\hline Yes & $24(4.62)$ & $30(5.77)$ & & \\
\hline Tumor size, $\mathrm{cm}$ & & & 1.205 & 0.272 \\
\hline$\leq 3$ & $156(30.00)$ & $157(30.19)$ & & \\
\hline$>3$ & $93(17.88)$ & $114(21.92)$ & & \\
\hline CIS & & & 0.030 & 0.863 \\
\hline Absent & $241(46.35)$ & $263(50.58)$ & & \\
\hline Present & $8(1.54)$ & $8(1.54)$ & & \\
\hline
\end{tabular}

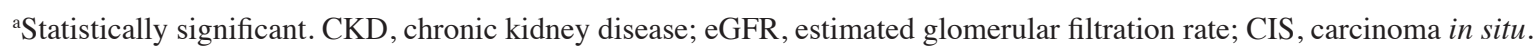


Table II. Univariate and multivariate analysis of risk factors for cancer-specific survival.

\begin{tabular}{|c|c|c|c|c|c|c|}
\hline \multirow[b]{2}{*}{ Variable } & \multirow{2}{*}{$\begin{array}{c}\text { Patients, } \\
\text { n }\end{array}$} & \multirow{2}{*}{$\begin{array}{c}\text { Recurrence, } \\
\mathrm{n}\end{array}$} & \multirow{2}{*}{$\begin{array}{c}\text { Univariate analysis } \\
\text { P-value }\end{array}$} & \multicolumn{3}{|c|}{ Multivariate analysis } \\
\hline & & & & Hazard ratio & $95 \% \mathrm{CI}$ & P-value \\
\hline Presence of hydronephrosis & & & $0.004^{\mathrm{a}}$ & 1.932 & $1.294-2.883$ & $0.001^{\mathrm{a}}$ \\
\hline Absence & 249 & 39 & & & & \\
\hline Presence & 271 & 66 & & & & \\
\hline Gender & & & $0.000^{\mathrm{a}}$ & 0.491 & $0.327-0.738$ & $0.001^{\mathrm{a}}$ \\
\hline Female & 291 & 43 & & & & \\
\hline Male & 229 & 62 & & & & \\
\hline Age, years & & & $0.028^{\mathrm{a}}$ & & & 0.437 \\
\hline$<50$ & 28 & 7 & & & & \\
\hline $50-60$ & 92 & 15 & & & & \\
\hline $60-70$ & 175 & 31 & & & & \\
\hline $70-80$ & 187 & 40 & & & & \\
\hline$\geq 80$ & 38 & 12 & & & & \\
\hline Preoperative renal function & & & 0.940 & & & \\
\hline No CKD $(e G F R \geq 60)$ & 228 & 44 & & & & \\
\hline Early CKD $(60>\mathrm{eGFR} \geq 15)$ & 255 & 52 & & & & \\
\hline End-stage CKD $(e G F R<15)$ & 37 & 9 & & & & \\
\hline Urinary cytology & & & 0.648 & & & \\
\hline Negative & 115 & 22 & & & & \\
\hline Positive & 250 & 57 & & & & \\
\hline Missing data & 155 & 26 & & & & \\
\hline Surgical approach & & & 0.743 & & & \\
\hline Open & 348 & 76 & & & & \\
\hline Laparoscopic & 172 & 29 & & & & \\
\hline Tumor architecture & & & $0.008^{\mathrm{a}}$ & & & 0.364 \\
\hline Papillary & 419 & 79 & & & & \\
\hline Sessile & 101 & 26 & & & & \\
\hline Multifocality & & & 0.560 & & & \\
\hline No & 412 & 84 & & & & \\
\hline Yes & 108 & 21 & & & & \\
\hline Location & & & 0.060 & & & \\
\hline Ureter & 256 & 58 & & & & \\
\hline Pelvis & 264 & 47 & & & & \\
\hline Tumor stage & & & $0.000^{\mathrm{a}}$ & 1.663 & $1.289-2.145$ & $0.000^{\mathrm{a}}$ \\
\hline $\mathrm{Ta}$ & 30 & 0 & & & & \\
\hline $\mathrm{T} 1$ & 150 & 13 & & & & \\
\hline $\mathrm{T} 2$ & 202 & 46 & & & & \\
\hline $\mathrm{T} 3$ & 135 & 41 & & & & \\
\hline $\mathrm{T} 4$ & 3 & 2 & & & & \\
\hline Node stage & & & 0.284 & & & \\
\hline No & 51 & 10 & & & & \\
\hline $\mathrm{Nx}$ & 458 & 91 & & & & \\
\hline $\mathrm{N}+$ & 10 & 3 & & & & \\
\hline Tumor grade & & & $0.010^{\mathrm{a}}$ & & & 0.172 \\
\hline G1 & 19 & 0 & & & & \\
\hline G2 & 310 & 56 & & & & \\
\hline G3 & 191 & 49 & & & & \\
\hline Tumor necrosis & & & $0.021^{\mathrm{a}}$ & 2.069 & $1.162-3.686$ & $0.014^{\mathrm{a}}$ \\
\hline No & 466 & 90 & & & & \\
\hline Yes & 54 & 15 & & & & \\
\hline
\end{tabular}


Table II. Continued.

\begin{tabular}{|c|c|c|c|c|c|c|}
\hline \multirow[b]{2}{*}{ Variable } & \multirow{2}{*}{$\begin{array}{c}\text { Patients, } \\
\mathrm{n}\end{array}$} & \multirow{2}{*}{$\begin{array}{c}\text { Recurrence, } \\
\mathrm{n}\end{array}$} & \multirow{2}{*}{$\begin{array}{c}\text { Univariate analysis } \\
\text { P-value }\end{array}$} & \multicolumn{3}{|c|}{ Multivariate analysis } \\
\hline & & & & Hazard ratio & $95 \% \mathrm{CI}$ & $\mathrm{P}$-value \\
\hline Tumor size, $\mathrm{cm}$ & & & 0.165 & & & \\
\hline$\leq 3$ & 313 & 59 & & & & \\
\hline$>3$ & 207 & 46 & & & & \\
\hline CIS & & & 0.318 & & & \\
\hline Absent & 504 & 103 & & & & \\
\hline Present & 16 & 2 & & & & \\
\hline Adjuvant therapy & & & 0.470 & & & \\
\hline No & 485 & 95 & & & & \\
\hline Yes & 30 & 8 & & & & \\
\hline
\end{tabular}

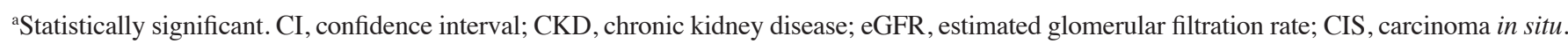
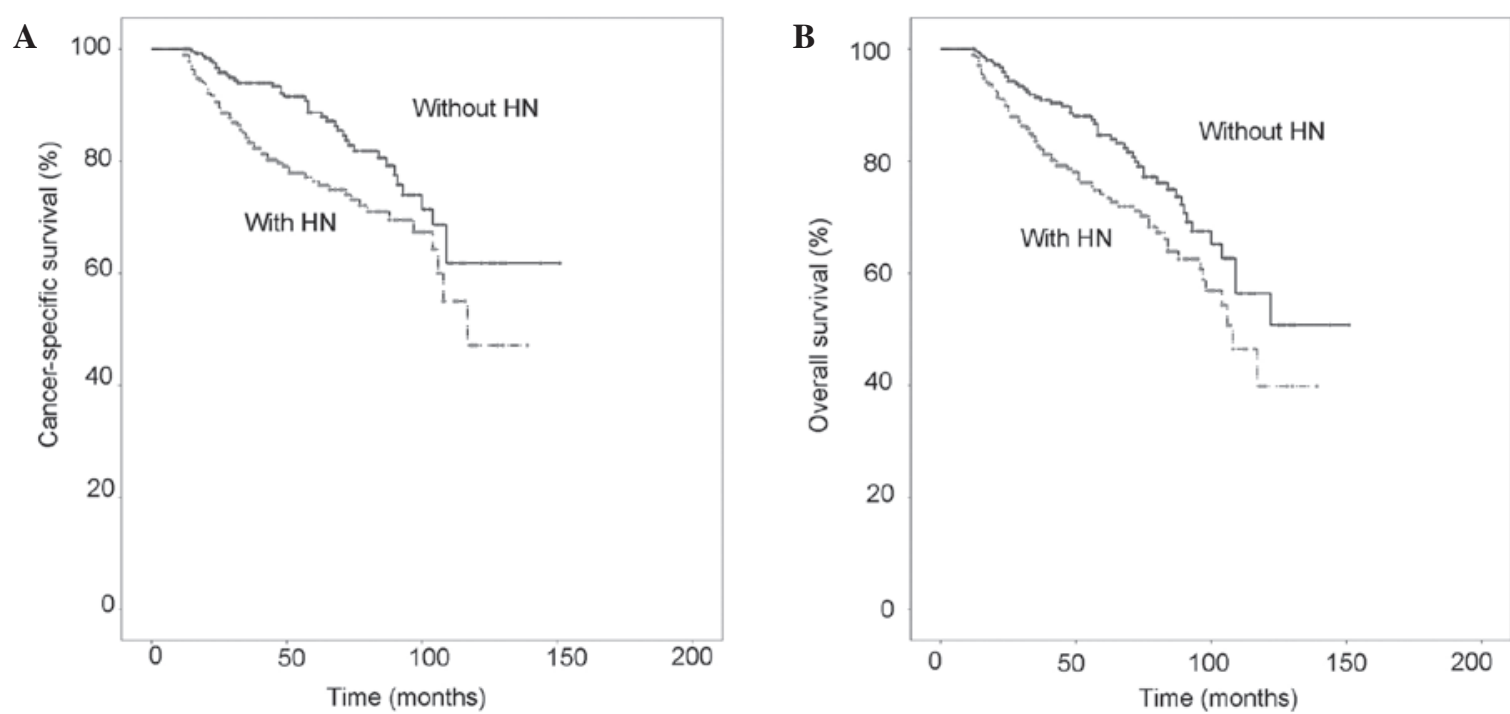

Figure 1. (A) Kaplan-Meier estimated cancer-specific survival curves stratified by the presence of HN (P=0.004). (B) Kaplan-Meier estimated overall survival curves stratified by the presence of $\mathrm{HN}(\mathrm{P}=0.009)$. $\mathrm{HN}$, hydronephrosis.
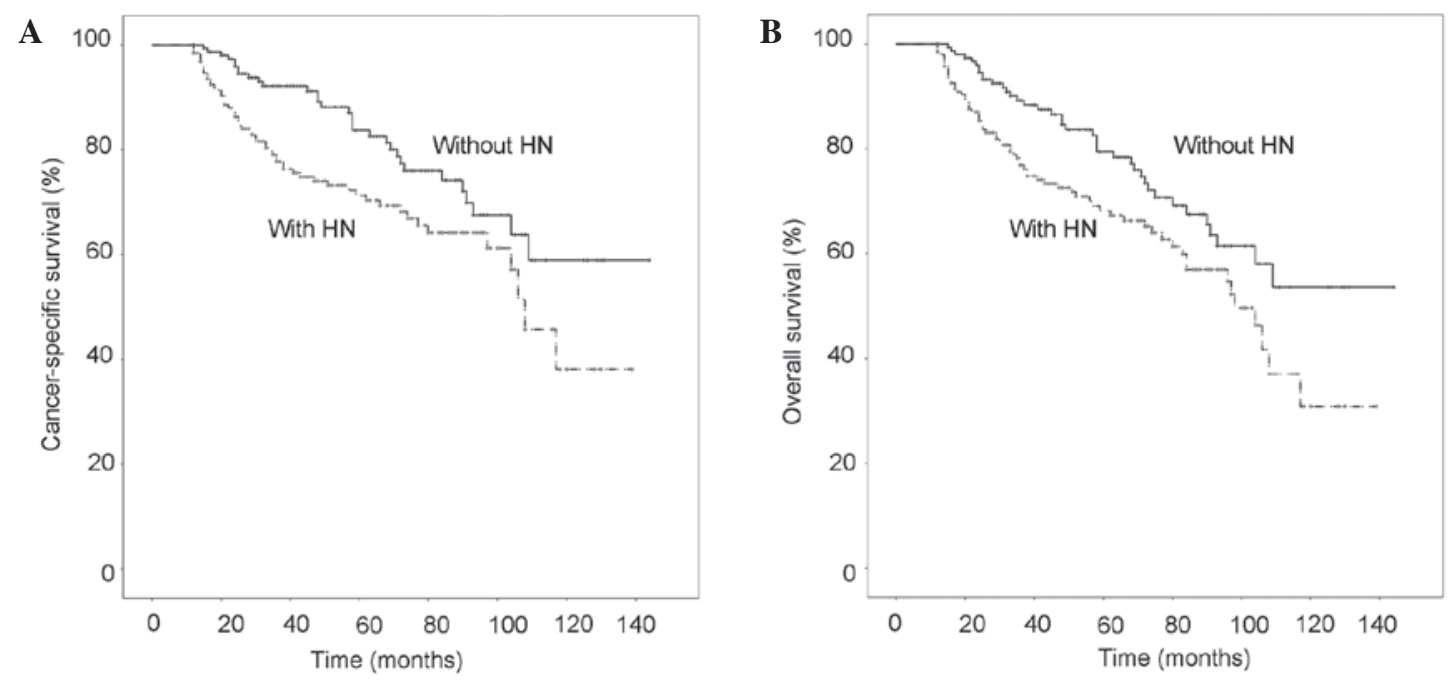

Figure 2. (A) Kaplan-Meier estimated cancer-specific survival curves in patients with muscle-invasive disease stratified by the presence of $\mathrm{HN}$ ( $\mathrm{P}=0.009)$. (B) Kaplan-Meier estimated overall survival curves in patients with muscle-invasive disease stratified by the presence of $\mathrm{HN}(\mathrm{P}=0.012)$. $\mathrm{HN}$, hydronephrosis. 
Table III. Univariate and multivariate analysis of risk factors for overall survival.

\begin{tabular}{|c|c|c|c|c|c|c|}
\hline \multirow[b]{2}{*}{ Variables } & \multirow{2}{*}{$\begin{array}{c}\text { Patients, } \\
\mathrm{n}\end{array}$} & \multirow{2}{*}{$\begin{array}{c}\text { Recurrence, } \\
\mathrm{n}\end{array}$} & \multirow{2}{*}{$\begin{array}{c}\text { Univariate analysis } \\
\text { P-value }\end{array}$} & \multicolumn{3}{|c|}{ Multivariate analysis } \\
\hline & & & & Hazard ratio & $95 \% \mathrm{CI}$ & P-value \\
\hline Presence of hydronephrosis & & & $0.009^{\mathrm{a}}$ & 1.587 & $1.111-2.265$ & $0.011^{\mathrm{a}}$ \\
\hline Absence & 249 & 52 & & & & \\
\hline Presence & 271 & 78 & & & & \\
\hline Gender & & & $0.000^{\mathrm{a}}$ & 0.604 & $0.426-0.858$ & $0.005^{\mathrm{a}}$ \\
\hline Female & 291 & 57 & & & & \\
\hline Male & 229 & 73 & & & & \\
\hline Age, years & & & $0.005^{\mathrm{a}}$ & 1.284 & $1.068-1.542$ & $0.008^{\mathrm{a}}$ \\
\hline$<50$ & 28 & 8 & & & & \\
\hline $50-60$ & 92 & 17 & & & & \\
\hline $60-70$ & 175 & 38 & & & & \\
\hline $70-80$ & 187 & 53 & & & & \\
\hline$\geq 80$ & 38 & 14 & & & & \\
\hline Preoperative renal function & & & 0.260 & & & \\
\hline No CKD $(e G F R \geq 60)$ & 228 & 48 & & & & \\
\hline Early CKD $(60>$ eGFR $\geq 15)$ & 255 & 68 & & & & \\
\hline End-stage CKD $(\mathrm{eGFR}<15)$ & 37 & 14 & & & & \\
\hline Urinary cytology & & & 0.385 & & & \\
\hline Negative & 116 & 26 & & & & \\
\hline Positive & 250 & 73 & & & & \\
\hline Missing data & 155 & 31 & & & & \\
\hline Surgical approach & & & 0.503 & & & \\
\hline Open & 348 & 96 & & & & \\
\hline Laparoscopic & 172 & 34 & & & & \\
\hline Tumor architecture & & & $0.015 \mathrm{a}$ & & & 0.262 \\
\hline Papillary & 419 & 100 & & & & \\
\hline Sessile & 101 & 30 & & & & \\
\hline Multifocality & & & 0.271 & & & \\
\hline No & 412 & 106 & & & & \\
\hline Yes & 108 & 24 & & & & \\
\hline Location & & & 0.110 & & & \\
\hline Ureter & 256 & 69 & & & & \\
\hline Pelvis & 264 & 61 & & & & \\
\hline Tumor stage & & & $0.000^{\mathrm{a}}$ & 1.581 & $1.265-1.976$ & $0.000^{\mathrm{a}}$ \\
\hline $\mathrm{Ta}$ & 30 & 4 & & & & \\
\hline $\mathrm{T} 1$ & 150 & 19 & & & & \\
\hline $\mathrm{T} 2$ & 202 & 57 & & & & \\
\hline T3 & 135 & 48 & & & & \\
\hline $\mathrm{T} 4$ & 3 & 2 & & & & \\
\hline Node stage & & & 0.519 & & & \\
\hline N0 & 52 & 11 & & & & \\
\hline $\mathrm{Nx}$ & 458 & 116 & & & & \\
\hline $\mathrm{N}+$ & 10 & 3 & & & & \\
\hline Tumor grade & & & $0.005^{\mathrm{a}}$ & & & 0.133 \\
\hline G1 & 19 & 0 & & & & \\
\hline G2 & 310 & 70 & & & & \\
\hline G3 & 191 & 60 & & & & \\
\hline Tumor necrosis & & & 0.137 & & & \\
\hline No & 466 & 115 & & & & \\
\hline Yes & 54 & 15 & & & & \\
\hline
\end{tabular}


Table III. Continued.

\begin{tabular}{|c|c|c|c|c|c|c|}
\hline \multirow[b]{2}{*}{ Variables } & \multirow{2}{*}{$\begin{array}{c}\text { Patients, } \\
\mathrm{n}\end{array}$} & \multirow{2}{*}{$\underset{\mathrm{n}}{\text { Recurrence, }}$} & \multirow{2}{*}{$\begin{array}{c}\text { Univariate analysis } \\
\text { P-value }\end{array}$} & \multicolumn{3}{|c|}{ Multivariate analysis } \\
\hline & & & & Hazard ratio & $95 \% \mathrm{CI}$ & P-value \\
\hline Tumor size, $\mathrm{cm}$ & & & 0.306 & & & \\
\hline$\leq 3$ & 313 & 76 & & & & \\
\hline$>3$ & 207 & 54 & & & & \\
\hline CIS & & & 0.344 & & & \\
\hline Absent & 504 & 127 & & & & \\
\hline Present & 16 & 3 & & & & \\
\hline Adjuvant therapy & & & 0.648 & & & \\
\hline No & 485 & 119 & & & & \\
\hline Yes & 30 & 9 & & & & \\
\hline
\end{tabular}

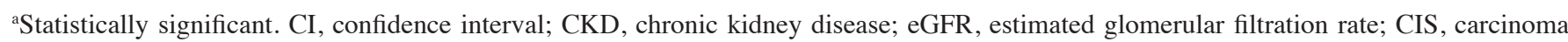
in situ.
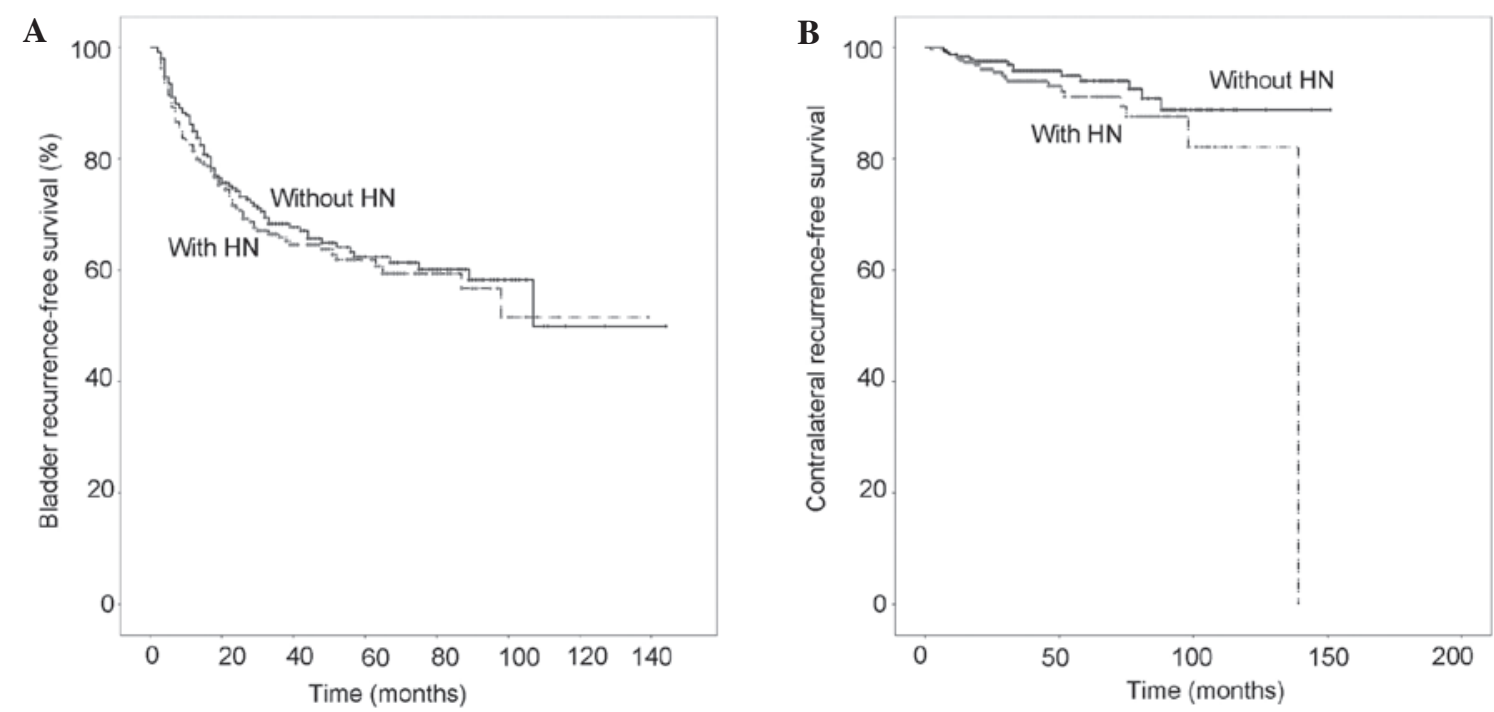

Figure 3. (A) Kaplan-Meier estimated bladder recurrence-free survival curves stratified by the presence of $\mathrm{HN}(\mathrm{P}=0.552)$. (B) Kaplan-Meier estimated contralateral upper tract urothelial carcinoma-free survival curves stratified by the presence of $\mathrm{HN}(\mathrm{P}=0.164)$. HN, hydronephrosis.

There were 340 patients with muscle-invasive disease ( $\mathrm{T}$ stage $\geq 2$ ), and 191 patients were diagnosed with histological grade 3 disease by final pathology. Preoperative HN was associated with advanced age $(\mathrm{P}=0.007)$, sessile tumor architecture $(\mathrm{P}<0.001)$, ureteral location $(\mathrm{P}<0.001)$, high tumor stage $(\mathrm{P}<0.001)$ and higher histological grade $(\mathrm{P}=0.002)$. No distribution differences in terms of gender, preoperative kidney function, multifocality, presence of carcinoma in situ (CIS) or tumor size were identified.

Survival outcomes and $H N$. During a median follow-up duration of 54 months (range, 12-151 months), 120 patients (23.1\%) died, including 105 patients $(20.2 \%)$ who succumbed to urothelial cancer. Of these patients, $78(65.0 \%)$ had preoperative HN. The 5-year CSS and OS rates for patients with HN were 86.9 and $86.2 \%$, respectively: Markedly lower than for patients without HN (93.3 and 91.9\%, respectively).
Kaplan-Meier estimated CSS and OS curves are shown in Fig. 1A and B. The presence of HN was a significant risk factor for poorer CSS and OS times according to univariate analysis $(\mathrm{P}=0.004$ and $\mathrm{P}=0.009$, respectively). In the multivariate analysis, the presence of $\mathrm{HN}$ remained a significant predictive factor for CSS and $\mathrm{OS}(\mathrm{P}=0.001$ and $\mathrm{P}=0.011$, respectively). The multivariate analysis also confirmed male gender, advanced age and higher tumor stage as risk factors for reduced survival (Tables II and III).

As higher tumor stage is a well-established predictor of survival (11), the predictive role of $\mathrm{HN}$ was analyzed only in the 340 patients with muscle-invasive disease ( $\mathrm{T} \geq 2)$ (Table III). Of the 189 patients with $\mathrm{HN}$, there were 68 mortalities, comprising 58 cancer-specific mortalities, during follow-up. By contrast, only 39 mortalities, including 31 cancer-specific mortalities, occurred among the remaining 151 patients without HN. The differences in CSS and OS times between the two groups were 
statistically significant $(\mathrm{P}=0.009$ and $\mathrm{P}=0.012$, respectively; Fig. 2A and B).

Pathology confirmed that 178 patients $(34.2 \%)$ had intravesical recurrence and 35 patients (6.7\%) had subsequent contralateral UTUC. Of the patients with HN, 99 experienced intravesical recurrence and 22 contralateral disease during follow-up, and there was no association between the presence of $\mathrm{HN}$ and bladder cancer recurrence-free survival time $(\mathrm{P}=0.552)$ or the development of contralateral carcinoma-free survival time $(\mathrm{P}=0.164)$ (Fig. 3A and $\mathrm{B})$.

\section{Discussion}

Preoperative HN can be present in bladder tumors and UTUCs. The incidence of $\mathrm{HN}$ in bladder tumors is reported to be $5.3-22.7 \%$, and the presence of $\mathrm{HN}$ has been demonstrated to be associated with poor pathological outcomes, tumor recurrence and progression (18-20). The presence of $\mathrm{HN}$ is more prevalent in UTUC than in bladder tumors $(52.1 \%$ in the current study), which may be because urinary obstruction is more likely to occur in the ureter from a small mass.

There have been a number of studies focused on the association between the presence of $\mathrm{HN}$ and clinicopathological characteristics and prognosis $(17,22-25,27)$. The majority of these studies have reported a predictive role of $\mathrm{HN}$ in poor pathological outcomes, however, there has been no consensus on the association between $\mathrm{HN}$ and poor prognosis. $\mathrm{Ng}$ et al (17) confirmed that $\mathrm{HN}$ was independently associated with cancer metastasis and cancer-specific mortality by preoperative multivariable analysis controlling for preoperative clinical features. However, their research was based on only 106 patients and HN was no longer an independent risk factor upon postoperative multivariable analysis. Hwang et al (25) reported that preoperative HN predicted poor prognosis in 114 patients; data on architecture, multifocality and preoperative renal function were unavailable. Ito et al (22) reported that 67 patients $(73.6 \%)$ exhibited HN in a retrospective study of 91 cases, and validated the correlation between $\mathrm{HN}$ and poor pathological outcomes, whilst a higher HN grade was not associated with disease-specific or metastasis-free survival. Bozzini et al (27) conducted a relatively large-scale study with 401 patients, however, $\mathrm{HN}$ was present in only $18.4 \%$ of patients and the median follow-up period was 26 months. Furthermore, whilst studies by Messer et al (23) and Brien et al (24) demonstrated that HN was associated with muscle-invasive and non-organ confined disease, these studies were lacking in follow-up data.

The proportions of $\mathrm{HN}$ reported in previous studies may differ due to the lack of clear criteria with which to evaluate $\mathrm{HN}$. Based on the current analysis, the presence of HN was associated with a number of poor pathological outcomes, including high tumor stage, high tumor grade and sessile tumor architecture. In addition, a greater number of tumors were located in the ureter in patients with $\mathrm{HN}$, and previous studies have demonstrated that patients with ureteral tumors have a poorer prognosis compared with those with renal pelvis tumors, after adjustment for a number of pathological variables $(28,29)$. A recent study attributed this difference in prognosis to the fact that ureteral tumors are more likely to have $\mathrm{HN}$ (30). According to univariate and multivariate survival analyses, the presence of $\mathrm{HN}$ was associated with poorer survival, which confirmed the role of $\mathrm{HN}$ as an independent risk factor for poor prognosis. Preoperative HN must be carefully evaluated as a significant predictive factor for prognosis as well as higher tumor stage and tumor grade. The present study observed no correlation between $\mathrm{HN}$ and bladder recurrence or contralateral UTUC, and no such association has been reported previously (31).

Using conservative surgeries, including segmental ureterectomy or endoscopic management, renal function may be preserved and perioperative complications with RNU avoided (32). Clinical consideration of advanced disease based on the presence of $\mathrm{HN}$ could allow physicians to better individually assess treatment options in UTUC; patients with HN may not be suitable candidates for less invasive surgical options. In addition, patients with locally advanced UTUC have significantly higher local recurrence and distant metastasis rates following RNU, compared with patients exhibiting early stage disease $(11,33)$. Such findings call for effective strategies for perioperative systemic therapy to improve survival. The presence of $\mathrm{HN}$ also indicates a need for aggressive treatment, including lymphadenectomy and systemic chemotherapy.

Neoadjuvant chemotherapy appears to achieve favorable oncological outcomes in high-risk patients $(15,16)$, while adjuvant chemotherapy confers minimal impact on OS or CSS $(34,35)$. In addition, not all patients are able to receive adjuvant treatment due to comorbidities and impaired renal function following RNU (36). Hoshino et al (37) found that patients with no $\mathrm{HN}$ or a lower grade of $\mathrm{HN}$ have a higher risk of missing the opportunity to undergo adjuvant chemotherapy for impaired renal function following RNU. Thus, if patients without $\mathrm{HN}$ are evaluated as high-risk (based on lymph node metastasis or higher biopsy grade) and systemic chemotherapy is considered, neoadjuvant chemotherapy is recommended before renal function becomes impaired.

The limitations of the current study include the retrospective design and data collection, and the lack of re-evaluation of a number of CT films. Therefore, the study cohort may be subject to selection and recall bias. The incidence of UTUC in the Chinese population is markedly higher compared with that of western populations, and the biology may differ (38). Although the mechanisms related to these ethnic differences are still not fully known, dietary exposure to toxins may play a major role (39). In addition, Chinese UTUC patients are more likely to be female, and females are less likely to be of an advanced pathological disease stage compared with males $(40,41)$. Despite its limitations, the present study is currently the largest to report on the predictive role of HN in UTUC patients, and the first study confirming an association between $\mathrm{HN}$ and poor prognosis after controlling for other clinical and pathological characteristics in a large sample.

In conclusion, preoperative HN is prevalent in UTUC. The presence of preoperative $\mathrm{HN}$ predicted poorer pathological outcomes and was a significant risk factor affecting survival. The evaluation of HN may therefore be informative for decisions concerning surgical strategies, and the presence of $\mathrm{HN}$ should raise the possibility of employing an aggressive treatment strategy. 


\section{Acknowledgements}

The present study was supported by grants from the Clinical Features Research of Capital (grant nos. Z121107001012154 and Z151100004015173), the Collaborative Research Foundation of Peking University Health Science Center and the College of Medicine, National Taiwan University (grant no.BMU20120318), the Natural Science Foundation of China (grant nos. 81172419 and 81372746), the Natural Science Foundation of Beijing (grant no. 7122183), and the Research Foundation of Peking University First Hospital (grant no. 2015QN026).

\section{References}

1. Siegel R, Naishadham D and Jemal A: Cancer statistics, 2012. CA Cancer J Clin 62: 10-29, 2012.

2. Pérez-Utrilla Pérez M, Aguilera Bazán A, Alonso Dorrego JM, et al: Simultaneous cystectomy and nephroureterectomy due to synchronous upper urinary tract tumors and invasive bladder cancer: Open and laparoscopic approaches. Curr Urol 6: 76-81, 2012.

3. Cummings KB: Nephroureterectomy: Rationale in the management of transitional cell carcinoma of the upper urinary tract. Urol Clin North Am 7: 569-578, 1980.

4. McLaughlin JK, Silverman DT, Hsing AW, et al: Cigarette smoking and cancers of the renal pelvis and ureter. Cancer Res 52: 254-257, 1992.

5. Colin P, Koenig P, Ouzzane A, et al: Environmental factors involved in carcinogenesis of urothelial cell carcinomas of the upper urinary tract. BJU Int 104: 1436-1440, 2009.

6. Cowan NC: CT urography for hematuria. Nat Rev Urol 9: 218-226, 2012.

7. Sobin L, Gospodarowicz M and Wittekind C (eds): Urological tumours. Renal pelvis and ureter. In: TNM Classification of Malignant Tumours. 7th revised edition. Wiley-Blackwell, Hoboken, NJ, pp258-261, 2009.

8. Rink M, Ehdaie B, Cha EK, et al; Bladder Cancer Research Consortium (BCRC); Upper Tract Urothelial Carcinoma Collaboration (UTUCC): Stage-specific impact of tumor location on oncologic outcomes in patients with upper and lower tract urothelial carcinoma following radical surgery. Eur Urol. 62: 677-684, 2012.

9. Cha EK, Shariat SF, Kormaksson M, et al: Predicting clinical outcomes after radical nephroureterectomy for upper tract urothelial carcinoma. Eur Urol 61: 818-825, 2012.

10. Roupret M, Babjuk M, Comperat E, et al; European Association of Urology: European guidelines on upper tract urothelial carcinomas: 2013 update. Eur Urol 63: 1059-1071, 2013.

11. Margulis V, Shariat SF, Matin SF, et al: Outcomes of radical nephroureterectomy: A series from the upper tract urothelial carcinoma collaboration. Cancer 115: 1224-1233, 2009.

12. Gadzinski AJ, Roberts WW, Faerber GJ and Wolf JS Jr: Long-term outcomes of nephroureterectomy versus endoscopic management for upper tract urothelial carcinoma. J Urol 183: 2148-2153, 2010.

13. Colin P, Ouzzane A, Pignot G, et al: Comparison of oncological outcomes after segmental ureterectomy or radical nephroureterectomy in urothelial carcinomas of the upper urinary tract: Results from a large French multicentre study. BJU Int 110: 1134-1141, 2012.

14. Murphy DM, Zincke H and Furlow WL: Primary grade 1 transitional cell carcinoma of the renal pelvis and ureter. J Urol 123: 629-631, 1980

15. Matin SF, Margulis V, Kamat A, et al: Incidence of downstaging and complete remission after neoadjuvant chemotherapy for high-risk upper tract transitional cell carcinoma. Cancer 116: 3127-3134, 2010.

16. Youssef RF, Shariat SF, Lotan Y, et al: Upper urinary tract urothelial carcinoma with loco-regional nodal metastases: Insights from the upper tract urothelial carcinoma collaboration. BJU Int 108: 1286-1291, 2011.

17. Ng CK, Shariat SF, Lucas SM, et al: Does the presence of hydronephrosis on preoperative axial CT imaging predict worse outcomes for patients undergoing nephroureterectomy for upper-tract urothelial carcinoma? Urol Oncol 29: 27-32, 2011.
18. Divrik RT, Sahin A, Altok M, Unlu N and Zorlu F: The frequency of hydronephrosis at initial diagnosis and its effect on recurrence and progression in patients with superficial bladder cancer. J Urol 178: 802-806, 2007.

19. Haleblian GE, Skinner EC, Dickinson MG, Lieskovsky G, Boyd SD and Skinner DG: Hydronephrosis as a prognostic indicator in bladder cancer patients. J Urol 160: 2011-2014, 1998.

20. Bartsch GC, Kuefer R, Gschwend JE, de Petriconi R, Hautmann RE and Volkmer BG: Hydronephrosis as a prognostic marker in bladder cancer in a cystectomy-only series. Eur Urol 51: 690-697, 2007.

21. Chen XP, Xiong GY, Li XS, Matin SF, Garcia M, Fang D, Wang TY, Yu W, Gong K, Song Y, et al: Predictive factors for worse pathological outcomes of upper tract urothelial carcinoma: Experience from a nationwide high-volume centre in China. BJU Int 112: 917-924, 2013.

22. Ito Y, Kikuchi E, Tanaka N, Miyajima A, Mikami S, Jinzaki M and Oya M: Preoperative hydronephrosis grade independently predicts worse pathological outcomes in patients undergoing nephroureterectomy for upper tract urothelial carcinoma. J Urol 185: 1621-1626, 2011.

23. Messer JC, Terrell JD, Herman MP, Ng CK, Scherr DS, Scoll B, Boorjian SA, Uzzo RG, Wille M, Eggener SE, et al: Multi-institutional validation of the ability of preoperative hydronephrosis to predict advanced pathologic tumor stage in upper-tract urothelial carcinoma. Urol Oncol 31: 904-908, 2013.

24. Brien JC, Shariat SF, Herman MP, Ng CK, Scherr DS, Scoll B, Uzzo RG, Wille M, Eggener SE, Terrell JD, et al: Preoperative hydronephrosis, ureteroscopic biopsy grade and urinary cytology can improve prediction of advanced upper tract urothelial carcinoma. J Urol 184: 69-73, 2010.

25. Hwang I, Jung SI, Nam DH, Hwang EC, Kang TW, Kwon DD and Ryu SB: Preoperative hydronephrosis and diabetes mellitus predict poor prognosis in upper urinary tract urothelial carcinoma. Can Urol Assoc J 7: E215-E220, 2013.

26. Ma YC, Zuo L, Chen JH, Luo Q, Yu XQ, Li Y, Xu JS, Huang SM, Wang LN, Huang W, et al: Modified glomerular filtration rate estimating equation for Chinese patients with chronic kidney disease. J Am Soc Nephrol 17: 2937-2944, 2006.

27. Bozzini G, Nison L, Colin P, Ouzzane A, Yates DR, Audenet F, Pignot G, Arvin-Berod A, Merigot O, Guy L, et al: Influence of preoperative hydronephrosis on the outcome of urothelial carcinoma of the upper urinary tract after nephroureterectomy: The results from a multi-institutional French cohort. World J Urol 31: 83-91, 2013.

28. Akdogan B, Dogan HS, Eskicorapci SY, Sahin A, Erkan I and Ozen H: Prognostic significance of bladder tumor history and tumor location in upper tract transitional cell carcinoma. J Urol 176: 48-52, 2006.

29. Ouzzane A, Colin P, Xylinas E, Pignot G, Ariane MM, Saint F, Hoarau N, Adam E, Azemar MD, Bensadoun H, et al: Ureteral and multifocal tumours have worse prognosis than renal pelvic tumours in urothelial carcinoma of the upper urinary tract treated by nephroureterectomy. Eur Urol 60: 1258-1265, 2011.

30. Zhang X, Zhu Z, Zhong S, Xu T and Shen Z: Ureteral tumours showing a worse prognosis than renal pelvis tumours may be attributed to ureteral tumours more likely to have hydronephrosis and less likely to have haematuria. World J Urol 31: 155-160, 2013.

31. Azémar MD, Comperat E, Richard F, Cussenot O and Rouprêt M: Bladder recurrence after surgery for upper urinary tract urothelial cell carcinoma: Frequency, risk factors and surveillance. Urol Oncol 29: 130-136, 2011.

32. Silberstein JL, Power NE, Savage C, Tarin TV, Favaretto RL, Su D, Kaag MG, Herr HW and Dalbagni G: Renal function and oncologic outcomes of parenchymal sparing ureteral resection versus radical nephroureterectomy for upper tract urothelial carcinoma. J Urol 187: 429-434, 2012.

33. Hall MC, Womack S, Sagalowsky AI, Carmody T, Erickstad MD and Roehrborn CG: Prognostic factors, recurrence and survival in transitional cell carcinoma of the upper urinary tract: A 30-year experience in 252 patients. Urology 52: 594-601, 1998.

34. Hellenthal NJ, Shariat SF, Margulis V, Karakiewicz PI, Roscigno M, Bolenz C, Remzi M, Weizer A, Zigeuner R, Bensalah K, et al: Adjuvant chemotherapy for high risk upper tract urothelial carcinoma: Results from the upper tract urothelial carcinoma collaboration. J Urol 182: 900-906, 2009.

35. Audenet F, Yates DR, Cussenot O and Roupret M: The role of chemotherapy in the treatment of urothelial cell carcinoma of the upper urinary tract (UUT-UCC). Urol Oncol 31: 407-413, 2013. 
36. O'Donnell PH and Stadler WM: The role of chemotherapy in upper tract urothelial carcinoma. Adv Urol 2009: 419028, 2009.

37. Hoshino K, Kikuchi E, Tanaka N, Akita H, Ito Y, Miyajima A, Jinzaki M and Oya M: Preoperative hydronephrosis: Independent predictor for changes in renal function following nephroureterectomy. Jpn J Clin Oncol 42: 202-207, 2012.

38. Wang SM, Lai MN, Chen PC, Pu YS, Lai MK, Hwang JS and Wang JD: Increased upper and lower tract urothelial carcinoma in patients with end-stage renal disease: A nationwide cohort study in Taiwan during 1997-2008. Biomed Res Int 2014: 149750, 2014.
39. Chen CH, Dickman KG, Moriya M, Zavadil J, Sidorenko VS, Edwards KL, Gnatenko DV, Wu L, Turesky RJ, Wu XR, et al: Aristolochic acid-associated urothelial cancer in Taiwan. Proc Natl Acad Sci USA 109: 8241-8246, 2012.

40. Chou YH and Huang CH: Unusual clinical presentation of upper urothelial carcinoma in Taiwan. Cancer 85: 1342-1344, 1999.

41. Yu W, Zhao YY, Shen Q, Yang XY, He Q, Song Y and Jin J: Gender-related differences in pathological characteristics of upper urinary tract urothelial carcinoma: Analysis of 597 cases. Beijing Da Xue Xue Bao 43: 522-524, 2011 (In Chinese). 